\title{
Empirical Research on the Service Quality of Traveling Websites
}

\author{
Yanyan WANG \\ Straits Academy, Minjiang University, Fuzhou,350102,China \\ email: nancy2004xw@sina..com
}

keywords: Traveling websites; Service quality factor, Empirical research

\begin{abstract}
The paper offers an empirical analysis on the service quality of the website of the Sun Moon Lake Scenic Area through questionnaires. The results show that the tangible factor, reactive factor, reliability factor and solicitude factor are the main factors that influence web browsers' satisfaction. The tangible factor and solicitude factor influence browsers' behavior, with the former determining the intention to revisit, and the latter determining intention of word-of-mouth. The research findings are significant for the design and development of traveling websites.
\end{abstract}

\section{Introduction}

With the development of the cross-straits economic relations, tremendous changes have taken place in the tourism industry in Taiwan. According to the statistics from Tourist Bureau of Taiwan, in Q1, 2010, mainland tourists in Taiwan had outnumbered that of Japanese tourists, enabling mainland to become the primary source of external tourists in the season. Till December, 2014, among the major sources of tourists in Taiwan, the number of tourists with sight-seeing as the purpose witnessed the highest growth rate of $55.83 \%$ in mainland China, followed by Korea and Hong Kong and Macau, with $10.89 \%$ and $9.56 \%$ respectively [1]. In the internet age, an increasing number of tourists acquire relevant information of the tourist spots through the internet [2]. Therefore, the quality of traveling websites will directly influence the travel experience of tourists in Taiwan. Meanwhile, according to the estimates of the World Tourism Organization, by 2020, China is expected to become the world's largest country in tourism, when $10 \%$ of the turnover in the tourism market will come from the internet [3]. Therefore, we will also need to look into the quality of traveling websites in mainland China. Stimulated by such a background, the paper set the website of the Sun Moon Lake Scenic Area as an example to explore the relationship between the service quality of traveling websites and behavior intentions of browsers. Through these, the paper aims to shed light to development and design of traveling websites, improvement of the service quality, as well as the cyber marketing of tourism products.

\section{Literature Review}

Origin of the SERVQUAL model - a measure of service quality of websites

The model of service quality of websites referred to in this paper is put forward based on the SERVQUAL theory, which is a new service quality evaluation system proposed by American marketing experts A. Parasuraman, Zeithaml and Berry in the service industry according to the comprehensive quality management theory.The American Marketing Association (AMA) defines service as sales or activities, interest or satisfaction provided alongside with general commodity sales. Parasuraman et al. concluded 10 factors that influence service quality, including reliability, reactivity, capability, accessibility, courtesy, communicability, credibility, security, comprehension and tangibility. Following this, Parasuraman et al. reduced these 10 factors to 5, which include tangibility, reliability, reactivity, assurance and solicitude, based on which he further developed and amended the service quality scale - SERVQUAL [4].Many scholars also claim that the five dimensions of SERVQUAL and corresponding items in the questionnaire cannot be generally applied. Instead, they will become valid only when adjusted according to the environment and features of an industry. Parasuraman and Grewal also suggest developing suitable items according 
to the feature of the service when applying SERVQUAL in the assessment of various industries. Besides, due to the different characteristics between websites and staff services, the definition and relative importance of different dimensions in SERVQUAL have also changed, which explains why most scholars assess information systems or service quality of websites with an amended SERVQUAL [5]. Therefore, the study, based on an adjusted scale according to the features of traveling websites and the industry, perceives the service quality of traveling websites to be five-dimensional including: (1) reliability, (2) solicitude, (3) tangibility, (4) reactivity and (5) technology [6].

\section{Satisfaction of websites}

Woodside, Frey and Daly (1989) suggest that customer satisfaction is the overall attitude derived from the consumption behavior, which reflects how much they like or dislike after purchase [7]. Fornell (1992) maintains that the level of satisfaction is an overall feeling that can be directly assessed [8]. Zeithaml and Bitner (1996) also point out that the level of customer satisfaction can be considered either as the single level of service they receive, or as an overall level [9]. The paper evaluates the customer satisfaction level of traveling websites through a single overall satisfaction scale.

\section{Behavior intentions}

For traveling websites, nothing will be meaningful if it cannot be transferred into actual behavior, be it improvement in the service quality of the website or increase in the satisfaction level. Therefore, the study on the extent to which indicators such as service values are able to predict customers' behavior intentions is a focus in consumers' behavior research. Further to this, the study aims at targeted improvement on the service quality of traveling websites through relevant analysis on the relationship between the service values of traveling websites and customers' behavior intentions. In the field of marketing, behavior intention mainly refers to customers' purchase intention and word-of-mouth communications, etc. While purchase intention has a direct influence on companies' sales performance, word-of-mouth communications refer to the form of value delivery between customers. When customers are relatively satisfied towards the customer value delivered by the company, they will 'recommend' it to other people around them. It is these customers who promote the value delivery from the company to the customers. Faced with the increasing competition, companies, in order to realize steady and sustainable development, should not only focus on customer satisfaction, but also customers' purchase intention and public praise [10]. In the empirical research, behavior intentions will be represented by the intention to revisit the website, intention to purchase tourism products, word-of-mouth effect and switching intention, among which the first three are positive intentions, and the last is a negative intention [11].

\section{Research Design}

\section{Research hypothesis}

Many empirical literatures show a positive correlation between service quality and level of customer satisfaction and their behavior intention. For instance, Parasuraman et al. (1988) argue that the higher the service quality perceived by the customers, the higher their satisfaction level [12]. Cronin and Taylor (1992) and Baker and Crompton (2000), supportive of this argument, suggest that the higher the service quality, the higher customers' satisfaction level, loyalty level and intention to repurchase [13][14]. According to arguments above, we hereby establish the following hypotheses:

H1: The higher the service quality of a website, the higher the level of customer satisfaction.

$\mathrm{H} 2$ : The higher the level of customer satisfaction, the higher the level of behavior intention.

H3: The higher the service quality of a website, the higher the level of behavior intention.

\section{Flow chart of the research}

As is shown by Fig. 1, the perceived service quality of websites is comprised of five dimensions: tangibility, reliability, reactivity, solicitude and technology, which respectively refer to: layout (tangibility), ability of the website to guarantee the service committed (reliability), ability to 
offer prompt response to customer needs (reactivity), ability to offer customized service according to customers' requirements (solicitude), and the sense of technology of the system (technology). The level of satisfaction refers to the customers' level of satisfaction with the service provided by the website. The customers' behavior intention refers to customers' purchase intention and word-of-mouth communication, which include four aspects: public praise, revisits, travel and switches.

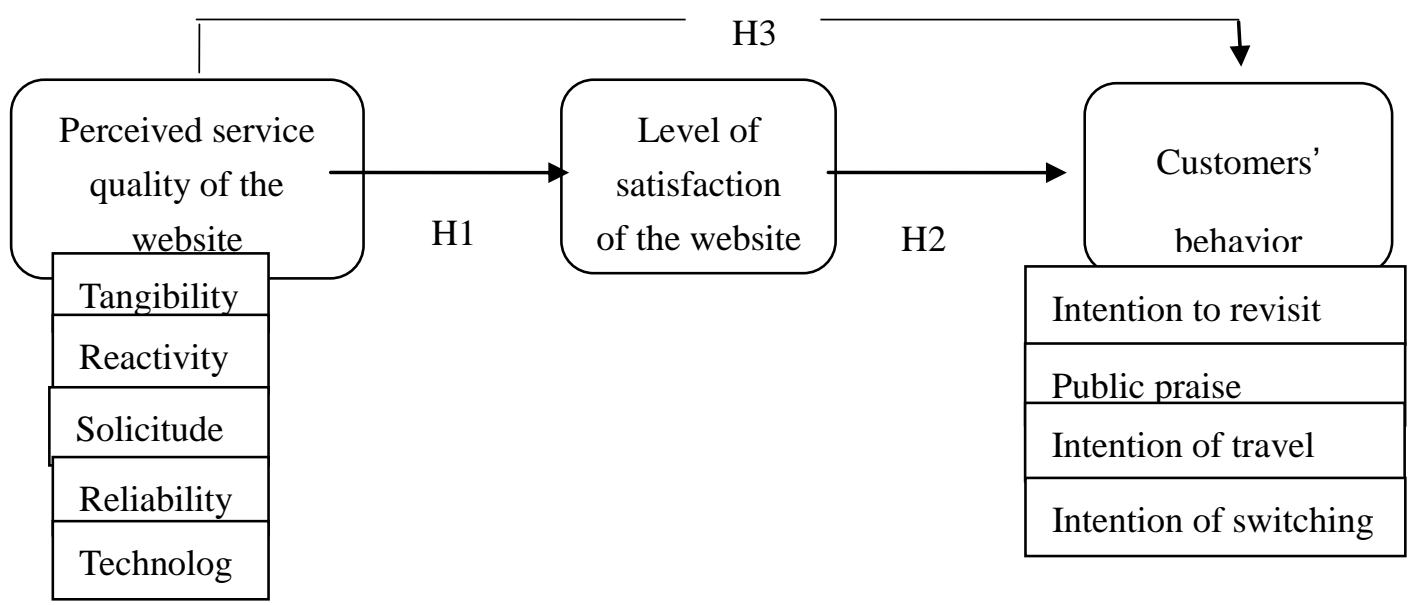

Fig. 1. Flow chart of the research (based on the study)

\section{Research method}

Data in this research is collected through questionnaires and analyzed with SPSS. We applied statistical methods such as Pearson correlation analysis and regression analysis in the statistical analysis of the 65 valid sample answer sheets. Each answer in the questionnaire is valued with Likert five-point scale, with five kinds of answers for each statement ranging from 'strongly agree', 'agree', 'not sure', 'disagree' to 'strongly disagree', marked as 5, 4, 3, 2 and 1 respectively. The total score for the attitude of each respondent is the sum of the score from each answer he/she provides, which can represent the strength of the respondent's attitude, or their different states on this scale.

\section{Data analysis}

\section{Research hypotheses proved}

H1: The higher the service quality of a website, the higher the level of customer satisfaction.

$\mathrm{H} 2$ : The higher the level of customer satisfaction, the higher the level of behavior intention.

H3: The higher the service quality of a website, the higher the level of behavior intention.

In the process of data analysis, as there are more than 1 question regarding service quality, level of satisfaction and behavior intention, these three variables were assigned as the average value for answers of the related set of questions, before put into the Pearson correlation analysis. The analysis shows that the value of sig, which is the correlation coefficient, is 0.000 . This signifies that the correlation is significant, hence the research hypotheses are proved. The scatter plot with the variables also shows a linear correlation between the three variables. 


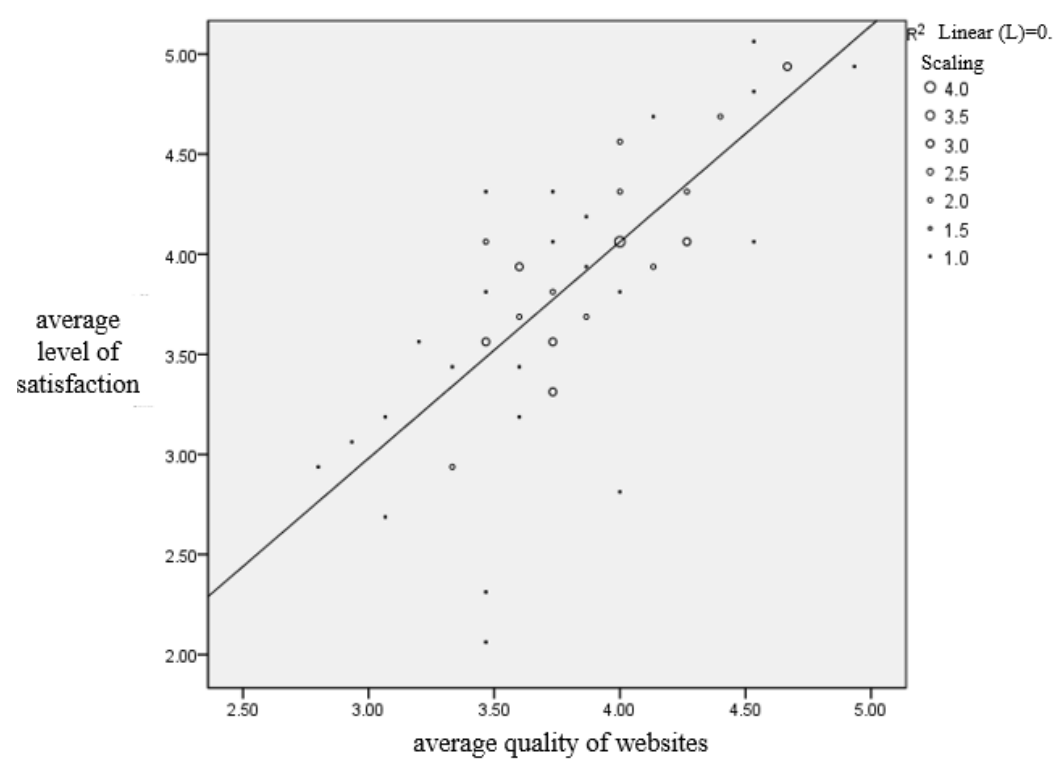

Fig. 2. Scatter plot between service quality of websites and their satisfaction levels

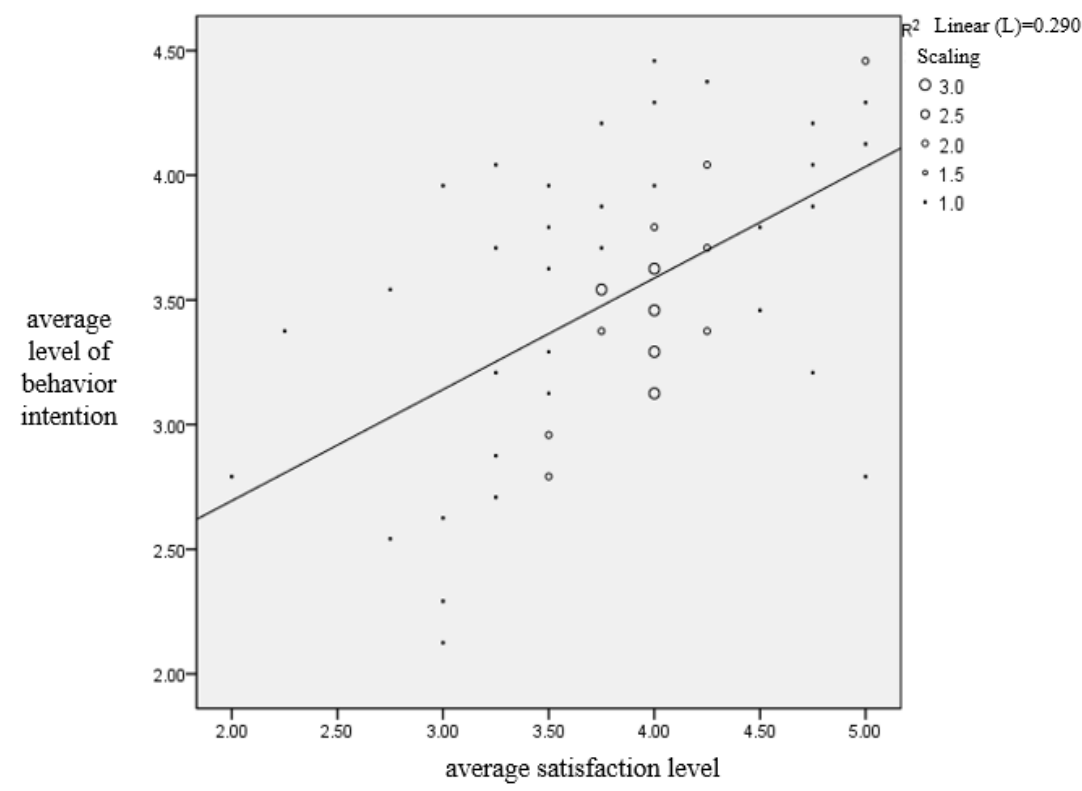

Fig. 3. Scatter plot between satisfaction level of websites and customers' behavior intention

From stepwise regression analysis, it was discovered that the tangible factor contributes remarkably to the satisfaction level of websites

From the scatter plots, it can be seen that there is a significant linear correlation between the service quality of websites, satisfaction level and behavior intention. Therefore, it is inferred that an equation of linear regression is suitable for describing such relationship. A stepwise regression analysis between the satisfaction level of websites and their service quality produced the following results:

Table 1.Regression table between factors regarding the service quality of websites and the satisfaction level of websites

\begin{tabular}{llccc} 
Model & $\begin{array}{r}\text { Unstandardized } \\
\text { Coefficients }\end{array}$ & $\begin{array}{r}\text { Standardized } \\
\text { Coefficients }\end{array}$ & t & Sig. \\
& B & Std. Error & Beta & \\
\hline
\end{tabular}




\begin{tabular}{lrrrrr}
\hline (Constant) & -.259 & .464 & & -.558 & .579 \\
Tangibility & .349 & .122 & .304 & 2.856 & $\mathbf{. 0 0 6}$ \\
Reactivity & .237 & .124 & .221 & 1.908 & .061 \\
Reliability & .261 & .119 & .226 & 2.201 & .032 \\
Solicitude & .223 & .109 & .221 & 2.053 & .044 \\
\hline
\end{tabular}

R Square $=0.577$

From Table 1, we conclude that the tangible factor, reactivity factor, reliability factor and solicitude factor can better explain the overall level of satisfaction of the website of the Sun Moon Lake Scenic Area. Independent variables with a significant influence on the satisfaction level of websites are tangible factor, reactivity factor, reliability factor and solicitude factor, among which the tangible factor has the most influence.

\section{The solicitude factor mainly influences customers' behavior intention}

Similarly, following a stepwise regression analysis between customers' behavior intention and factors regarding the service quality of websites, it was discovered that the solicitude factor and the tangible factor of the website of the Sun Moon Lake Scenic Area can better explain customers' behavior intention, among which the solicitude factor has major influence.

Table 2 .Regression table

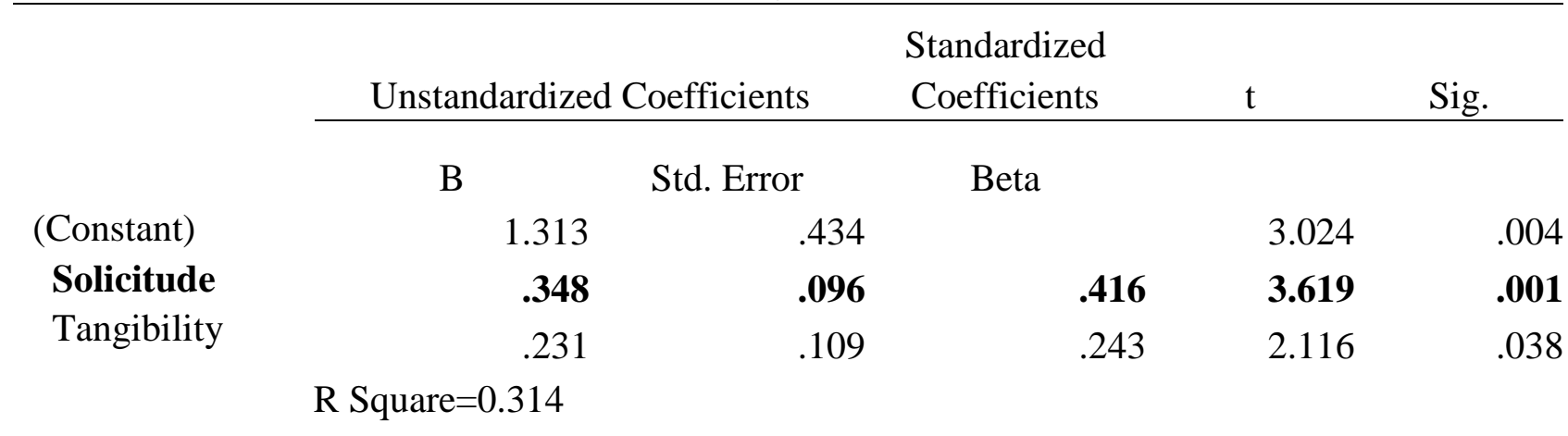

a. The tangible factor is the main influencing factor for the intention to revisit

Customers' behavior intention can be further classified into intention to revisit, intention of word-of-mouth and intention of travel. Respective stepwise regression analyses between each of these three intentions and factors regarding the service quality of websites produced the following results.

Table 3.Regression table

\begin{tabular}{|c|c|c|c|c|c|c|}
\hline \multirow{5}{*}{ Model } & & \multicolumn{2}{|c|}{$\begin{array}{c}\text { Unstandardized } \\
\text { Coefficients }\end{array}$} & \multirow{2}{*}{$\begin{array}{c}\begin{array}{c}\text { Standardized } \\
\text { Coefficients }\end{array} \\
\text { Beta }\end{array}$} & \multirow[b]{2}{*}{$\mathrm{t}$} & \multirow[b]{2}{*}{ Sig. } \\
\hline & & B & Std. Error & & & \\
\hline & (Constant) & .721 & .561 & & 1.285 & .204 \\
\hline & Tangibility & .396 & .139 & .335 & 2.844 & .006 \\
\hline & Technology & .305 & .126 & .286 & 2.423 & .018 \\
\hline
\end{tabular}

a Dependent Variable: intention to revisit

From the table, it can be observed that the tangible factor and the technology factor decides customers' intention to revisit, among which the tangible factor has major influence.

b. The solicitude factor is the major influencing factor for the intention of word-of-mouth

Table 4 Regression table

$\begin{array}{lllll}\text { Model } & \text { Unstandardized Coefficients } & \text { Standardized } & \text { t } & \text { Sig. }\end{array}$




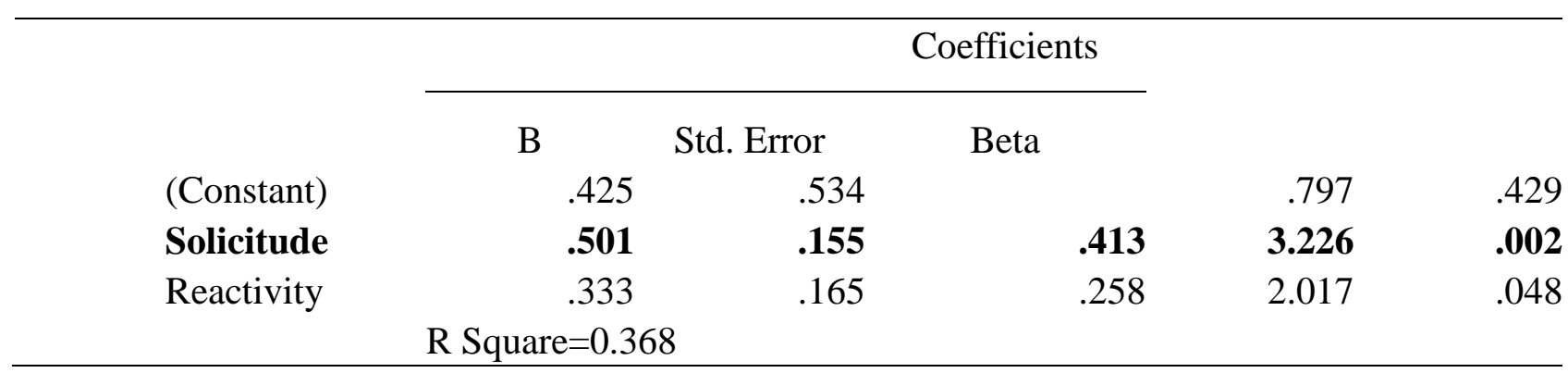

a Dependent Variable: intention of word-of-mouth

From the table(Regression table between factors regarding the service quality of websites and customers intention of word-of-mouth), it can be observed that the solicitude factor and the reactivity factor decides customers' intention of word-of-mouth, among which the solicitude factor has major influence.

\section{Conclusions}

The tangible factor is the most important factor among all factors regarding the service quality of websites. In the design and development of the website, the tangibility factor bears the most importance.The tangibility factor mainly refers to whether the layout of the website is attractive, and whether information catalogues are clear. Therefore, more effort should be taken in the design of the layout of traveling websites.

To increase the satisfaction level of the website, attention should be paid to the tangibility factor, reactivity factor, reliability factor and solicitude factor.According to the results of the regression analysis, the satisfaction level of the website is related with four factors: the tangibility factor, reactivity factor, reliability factor and solicitude factor, which is why these factors should be paid attention to in the design and development of the website. Apart from the tangibility factor, the reactivity factor refers to the prompt response to customers' needs; reliability factor means the content on the website, including words, pictures, graphs, video clips and animations, should be clearly marked out; the solicitude factor mainly means the website should provide customized service according to customers' needs. These can all effectively improve the satisfaction level of the website.

To increase the intention to revisit, attention should be paid to the tangibility factor and technology factor; whereas to improve public praise, attention should be paid to the solicitude factor and reactivity factor.According to the results of the regression analysis, the tangible factor and technology factor have a close relationship with the intention to revisit the website. Therefore, in order to effectively improve the revisiting rate, these two factors should be taken full consideration of. The tangibility factor is mainly related to layout, and the technology factor refers to providing user-friendly interactive interface on the traveling websites, including hyperlinks for queries, and multimedia functions such as Flash and Java. Similarly, if the website is developed and maintained to meet customers' personalized needs and to ensure a smooth channel for their feedback and communication, its word-of-mouth will be effectively improved.

\section{References:}

[1] Tourist Bureau of Taiwan. Monthly and Annual Review of Tourism Market, December, 2015[EB/OL] 2015-02-05: http://admin.taiwan.net.tw/statistics/release_d.aspx?no=136\&d=5571

[2] Xiao Liang, Zhao Liming. Image of Tourist Destinations in Taiwan on the Internet [J]. Tourism Tribune, 2009, 24(3):75-81

[3] Wu Xiaolin, Zhou Xuejin. Literature Review of Studies on Traveling Websites [J]. Business Culture, 2008, 07: 179-179

[4][12] Parasuraman, A., Zeithaml, V. A. and Berry, L. L., "SERVQUAL: a multiple-item scale for 
measuring consumer perceptions of service quality", Journal of Retailing, 1988, 64(1):12-40.

[5][6] Chi Wenhai, Yang Zongru, He Chunsheng. Research on the Relationship between Service Quality, Viewers' Satisfaction Level and Loyalty Level of News Websites [J], Quality Journal, 2007, 14(3): 285-299.

[7] Woodside, A. G., Frey, L. L. and Daly, R. T., Linking service quality, customer satisfaction, and behavior intention, Journal of Health Care Marketing, 1989, 9(1):5-17.

[8] Fornell, C., A national customer satisfaction barometer: the Swedish experience, Journal of Marketing,,1992,56(1):6-21.

[9] Zeithaml, V. A., Berry, L. L. and Parasuraman, A., "The behavioral consequences of service quality", Journal of Marketing, 1996, 60(1): 31-46.

[10][11] Liu Huiyan, 2011, Research on the Relationship between Perceived Value of Traveling Websites and Behavior Intention. Master's Thesis, East China Normal University

[13] Cronin, J. J. and Taylor, S. A., 1992, Measuring service quality: a reexamination and extension, Journal of Marketing, 56, 55-68.

[14] Baker, D. A. and Crompton, J. L., 2000, Quality, satisfaction and behavior intentions, Annals of Tourism Research, 27, 785-804. 